Article

\title{
The Devil Is in the Details: Linking Home Buyout Policy, Practice, and Experience After Hurricane Sandy
}

\author{
Sherri Brokopp Binder ${ }^{1, *}$ and Alex Greer ${ }^{2}$ \\ ${ }^{1}$ BrokoppBinder Research \& Consulting, Allentown, PA 18102, USA; E-Mail: sbinder@brokoppbinder.com \\ 2 Department of Political Science, Oklahoma State University, Stillwater, OK 74074, USA; E-Mail: alex.greer@okstate.edu \\ * Corresponding author
}

Submitted: 30 August 2016 | Accepted: 30 October 2016 | Published: 28 December 2016

\begin{abstract}
Federal housing recovery policy bounds many of the decisions made by households after a disaster. Within this policy domain, home buyout programs are increasingly used to encourage residents to permanently relocate out of areas considered at risk for future hazards. While buyouts offer homeowners and governments potential benefits, research exploring the impacts of these policies is limited. In this paper, we present an in-depth examination of the community experience of buyouts, a perspective that is noticeably lacking in the literature. Using data from two mixed-method empirical studies, we explored the implications of buyout program design and implementation for Oakwood Beach, New York, a community offered a buyout after Hurricane Sandy. We found that design decisions made at program conception significantly impacted participants' experience of the buyout, including their understanding of program goals and their progression through the buyout and relocation process. We conclude with recommendations for future buyouts, including increased inclusion of affected communities in the process of and pre-event planning for recovery, along with recommendations for future research.
\end{abstract}

\section{Keywords}

buyout; disaster recovery; housing policy; Hurricane Sandy; planning for recovery; relocation

\section{Issue}

This article is part of the issue "Disaster Policies and Governance: Promoting Community Resilience", edited by Naim Kapucu (University of Central Florida, USA) and Abdul-Akeem Sadiq (Indiana University-Purdue University Indianapolis, USA).

(C) 2016 by the authors; licensee Cogitatio (Lisbon, Portugal). This article is licensed under a Creative Commons Attribution 4.0 International License (CC BY).

\section{Introduction}

Home buyout programs facilitate the permanent relocation of residents out of areas considered at risk for future disasters. In their most basic form, buyout programs give homeowners the opportunity to sell their homes to a local implementing agency and relocate, ideally to a less hazardous area. While these programs are federally funded, they are implemented by municipal, county, or state agencies, and the land purchased through buyouts is converted into open space in perpetuity. In theory, then, home buyouts mitigate against future hazards by reducing the number of households at risk and increasing the amount of natural mitigation in place. These programs have been in use in the U.S. since the late 1970s, beginning with the relocation of flooded homes and businesses in Soldiers Grove, WI (David \& Mayer, 1984; Tobin \& Peacock, 1982).

Several states and communities have implemented buyouts in the intervening years, though our understanding of how these programs impact households and communities remains limited. This is due, in part, to a dearth of empirical research and limited evaluations of past programs. While few studies have examined the risks of buyout programs specifically, previous studies have found displacement to be associated with a range of social costs including losses in homeownership, social networks, access to healthcare, employment, income, and physical and mental health (Blaze \& Shwalb, 2009; Hori \& Schafer, 2009; Mortensen, Wilson, \& Ho, 2009; Riad \& 
Norris, 1996; Sanders, Bowie, \& Bowie, 2003; Weber \& Peek, 2012). These risks may be exacerbated for individuals and households who relocate permanently as compared to temporarily (Badri, Asgary, Eftekhari, \& Levy, 2006; Blaze \& Shwalb, 2009; Milne, 1977; Yzermans et al., 2005), for those who relocate outside their original community (Hori \& Schafer, 2009; Kessler et al., 2008), and for those who experience ecological stress (e.g. food shortages, overcrowding) while displaced and in the relocation process (Riad \& Norris, 1996). Given the potential risks associated with relocation, then, we would argue that a primary goal of any buyout effort, beyond reducing hazard exposure, should be to minimize these risks for participating households.

Further, given their substantive history and on-going use in the U.S., buyouts should show evidence of improvement over time. In a previous study (Greer \& Binder, 2016), we used policy learning theory to explore the extent to which these policies and programs had iterated over time. We examined eight buyout programs implemented between 1978 and 2005, and compared them according to key design features including primary funding source(s), number of homes purchased, duration, criteria for inclusion, use of financial incentives and disincentives, and degree of government involvement. We found little evidence of policy learning across buyout programs. Rather, the programs were designed and implemented independently with limited influence from past programs, with minimal guidance from federal funding agencies, and by local implementing agencies that lacked experience purchasing hazard-prone properties.

In this paper we contribute to the nascent literature on home buyout policy by applying case study methodology to examine how program design affects household experience, a question on which the overall success of buyouts hinges. We use the framework presented in our previous study of policy learning in buyouts as a starting point for understanding these processes. We begin by detailing a home buyout program implemented in New York after Hurricane Sandy, providing an overview of how Sandy affected the area and the relevant features of the buyout program. Next, we describe our methodology for exploring New York's buyout based on our framework. Then, we present data on how selection criteria, financial incentives, government involvement, the buyout program progression, and the perceived voluntariness of the program all influenced lived experiences for participating households. We conclude by discussing study implications and by offering recommendations for moving forward.

\section{Background}

On October 29, 2012, Hurricane Sandy made landfall in southern New Jersey, resulting in 159 fatalities and $\$ 50$ billion dollars in damages in the U.S. (Hurricane Sandy Rebuilding Task Force, 2013). Sandy was primarily a storm surge event, making it a monumental housing disaster that damaged or destroyed 650,000 homes and displaced residents for many months. In response, New York developed a home buyout program to transform portions of the state's coastal flood zones into preservation land (Kaplan, 2013; New York State Homes and Community Renewal [NYHCR], 2013). In its original form, the buyout plan offered $100 \%$ of a home's pre-storm value for substantially damaged homes (damaged beyond $50 \%$ of their value) located in the highest risk coastal areas (known as "V Zones" on the Federal Emergency Management Agency [FEMA] flood maps) and to substantially damaged homes located within the 500-year floodplain (NYHCR, 2013). The buyout program was later adjusted to apply only to homes within the $V$ Zones, while substantially damaged homes within the 500-year floodplain were eligible for a separate acquisition program ${ }^{1}$ (Governor's Office of Storm Recovery [GOSR], 2014). While a large number of homes were technically eligible for the buyout, the state ultimately selected only ten communities for buyouts, including three in New York City (NY Rising, 2014).

Homeowners in the eligible communities who opted to enroll in the buyout program had their homes appraised by a private company contracted by the state and received an offer based on that appraisal. To encourage participation in the selected communities, the state offered financial incentives in areas it designated as "enhanced buyout zones", defined as "areas at highest risk in the floodplains that are determined to be among the most susceptible to future disasters" (GOSR, 2014, p. 10). Homeowners could then accept the appraised value or hire a private appraiser (at their own expense) and appeal the offer. For those who accepted a buyout offer, a closing date was set and the property transferred to the state. Homeowners were responsible for finding and relocating to a new home once the property transfer was complete. In keeping with the requirements of the U.S. Department of Housing and Urban Development (HUD), which funded the buyout, the state was responsible for demolishing the purchased homes and converting the property to open space. As of July 2015, the state had purchased 713 homes through the buyout program (GOSR, personal communication, July 7, 2015).

\section{Methods}

In this paper, we present a case study of Oakwood Beach, a coastal community in New York City where most residents opted to participate in the state's buyout program. Yin (2013) suggests that case studies are appropriate when asking "how" or "why" questions, using multiple data sources to explore phenomena in a non-experimental setting. This study focuses specifically on how programmatic design choices impact household buyout experiences, and utilizing case study methodology allowed us to gather in-depth, experiential data surrounding a single program (Berg \& Lune, 2012, p. 337).

\footnotetext{
${ }^{1}$ Property acquisitions, while otherwise similar to buyouts, allow the state to resell and redevelop purchased properties.
} 
Data presented here are drawn from two mixedmethod studies that explored housing recovery and decision-making in the wake of Hurricane Sandy. We used three data sources to understand the experiences of residents: observations, surveys, and in-depth, semistructured interviews. We conducted extensive observations of Oakwood Beach, including attending community meetings and home inspections, touring damaged homes, and spending time with residents in the area. We conducted two surveys. We collected the first survey April-August 2013, utilizing a two-step sampling method that included systematic random door-to-door sampling supplemented by surveys collected at local community events. The second survey was conducted from MayJuly 2014 using a modified version of Dillman's (1978) methodology that included mailing a survey to every household within the buyout zone and homeowners on adjacent streets. By mailing the survey to participants, we were able to reach households that were displaced or no longer living in their pre-Sandy home. Both surveys included closed-ended questions that explored factors influencing buyout acceptance and open-ended questions that probed experiences with and perceptions of the buyout program. We bound our discussion here to the more relevant open-ended questions. In total, we received open-ended responses from 127 households. To complement our survey data, we conducted in-depth, semi-structured interviews with Oakwood Beach residents. While we were also able to speak with HUD and local officials about the design and implementation process, FEMA, the state of New York, and ProSource Technologies, a Minnesota-based firm the state of New York contracted to run the program, denied our numerous interview requests.

We utilized both inductive and deductive coding processes to explore the open-ended survey and interview data. Initially, we used inductive, descriptive coding to capture the major topics in our data in a word or phrase (Saldaña, 2012, p. 88). Next, we used deductive, elaborative coding to explore the ways buyout participants experienced the buyout program, including how the design of the buyout program influenced their experience, perspective, and opinion of the program. Elaborative coding allows for the use of deductive codes from previous studies, thereby adding depth to study findings (Saldaña, 2012, p. 229). We built our deductive codes to mirror key dimensions of buyout programs based on prior work exploring historical development and variation across buyouts (Greer \& Binder, 2016).

\section{Case Study of New York's Post-Sandy Home Buyout Program}

In this section we present findings related to the implications of program design and implementation in a community context. Focusing on one buyout in one community, we examine how key elements of buyout design influence the buyout experience for affected house- holds. These elements include the criteria for inclusion in the program, the financial incentives offered, the government's involvement in the buyout process, the progression of the buyout program, and the perceived voluntariness of the program. We present qualitative data that provide insight into the experience of residents of Oakwood Beach related to each of these programmatic elements.

\subsection{A Separation of One Street}

As was the case with previous buyouts, the criteria for inclusion in New York's buyout was initially broadly conceived, inclusive of substantially damaged homes within the 100- and 500-year floodplains. The geographic focus of the program shifted and shrank over time, however, such that the buyout was eventually extended to only a limited number of purposely-selected communities. These decisions were contentious. Several communities within New York City that vocally and actively pursued inclusion in the State's buyout, for example, were ultimately excluded from the program (Rizzi, 2014).

Even within Oakwood Beach, which was designated as the pilot community for the buyout program, decisions about which properties to include were controversial. The initial enhanced buyout zone designation in Oakwood Beach included approximately 165 properties in the coastal Fox Beach neighborhood (Fox Beach 165, 2013). Over time the buyout zone shifted, though neither the state nor the city offered residents a clear explanation of why the line of inclusion was drawn where it was. Dissatisfied with the original delineation, some residents whose properties were located just outside of the buyout zone organized, gathered signatures, and petitioned to be included in the buyout, though most of these efforts were unsuccessful. Ultimately, the buyout zone included the original properties in the Fox Beach neighborhood, along with approximately 115 additional homes in some, but not all, of the areas immediately adjacent to Fox Beach.

From the community's perspective this process seemed arbitrary at best, which was a point of significant frustration for residents on both sides of the line. Participants struggled to understand the "haphazard" decisions related to the inclusion and exclusion of properties, and described the impacts of these decisions on their families and community:

"We fell short just $50 \mathrm{ft}$. from the buyout....The politicians told us we were in Oakwood and not Oakwood Beach. In the meantime, we receive these surveys we fill out stating Oakwood Beach. This is the problem and pitfall unfortunately for my family. My home was on the market before the hurricane. My child lives with a life threatening condition. Our home was difficult to sell at the market. Now on a short sale. We are on a deficit.

Oh, yeah there was a separation of one street. There was even a separation on one block where one side 
of the street was a part of the buyout and the other side of the street was not....So the way it was zoned, I honestly don't know."

\subsection{Here's Rock, Here's Hard Place, Here's Us Right in the Middle}

New York used financial incentives to encourage participation in the buyout. While these financial incentives were sizeable relative to past programs, the incentives were not static. As originally designed, residents in enhanced buyout areas were eligible for incentives equal to a maximum of $25 \%$ of the sale price of the home (GOSR, 2014; Office of Community Renewal, 2013). This included a $10 \%$ incentive for designated high-risk areas, a $5 \%$ incentive if they purchased and relocated to a property within the same county (or within New York City, for city residents), and a $10 \%$ incentive for clusters of two to ten homes where owners of adjacent properties located within a V Zone collectively agreed to relocate. The $10 \%$ incentive for clusters of homes was later dropped, leaving buyout participants eligible to receive incentives of up to $15 \%$ of the sale price of their home.

Even with this decrease in available incentives, participants generally described the incentives as a positive component of the program. As one resident stated, "the government's gonna buy us out, they're gonna give us $10 \%$ above pre-storm, $5 \%$ if you stay [on Staten Island]. So financially, with that, we should be okay." At the same time, however, the incentive structure was a source of confusion for participants, few of whom could explain it clearly. Participants described being provided confusing and dated information about the amount of incentives available, and they gave varying, and often misinformed, explanations of eligibility requirements:

"So, I was originally told that we would get $25 \%-10$, 10 , and 5 -on top of pre-storm value. Now down the line, that changed. That became $15 \%$.

And then, because we're in an enhanced, what's called, it's called an enhanced area? Because we've had problems before? And we've had deaths in the area?...It's called enhanced. We, if you sell your house to them, you get an extra $10 \%$. Whatever the amount is. And if you buy a house, before, like, the complete closing? Before, you have a certain amount of time. And you stay on the island, or you stay in the area, you get another 5\%."

While the incentives were seen as helpful, they did not alleviate participants' financial concerns. Oakwood Beach was a relatively affordable community in the competitive New York City market, which had allowed residents to purchase homes with yards and other amenities that would have been beyond their reach in other areas of the city. After Sandy, finding comparable, affordable housing elsewhere was a challenge even with the financial incentives provided through the buyout. Participants described how this, in conjunction with other Sandy-related stressors, left them with few good options:

"Market changed and it was not enough to buy the same type of house in better neighborhood far from water. Very stressful was process with mortgage company: show that you have enough money on your account, they don't trust the contract of Buyout Program....Eventually I am not happy because of all extra expenses which appeared because of moving out and in. My 'dream' to pay off the mortgage of former house before retirement was gone and now my current house I will be unable to pay off. On the top of everything my marriage collapsed. It was too much for my husband. P.S. sorry for my English.

Because now we can't go that high on an older house, 'cause we have to keep money aside, because there's no warranties with anything. So, what if we walk in and two weeks down the road the boiler decides to go on the fritz, or, you know, the roof starts to leak. You know....So, that's limiting what we can buy now. You know, here's rock, here's hard place, here's us right in the middle."

The dollar amount received from the buyout, in effect, was not what residents felt was most important. Rather, what mattered was whether the buyout enabled them to replace the home they lost.

\subsection{Nobody's Telling Us Anything}

There was relatively little government involvement in New York's buyout compared to past programs, and property transfers closely resembled private sales. It is not clear why the state opted to follow this model, but among buyout participants it may have contributed to a sense that the government was detached from the process and unavailable to the community. In their interactions with government agencies and officials, participants reported receiving conflicting information and being unable to get answers to questions that directly influenced their housing recovery decisions. One participant simply stated "That's the problem. Nobody knows nothing. There's nowhere to go to get information."

Participant: "We waited two and a half hours, stood on line, talked to the FEMA guy? And we had our friend with us...so this way, when we asked a question, got an answer, she could help us remember....And we walked in, and he said, well, who are you. And we told him who we were. Well who's this, and we said a friend of ours. He said well she can stay as long as you guys don't ask any questions. And we were like....Yeah, it, it'd be too much for him to handle for us to ask questions. And I'm like, but what am I sittin' here for two and a half hours on line for if I can't ask any questions? 
So he let us ask questions, but basically gave us the same answers as we had....We waited for two and a half hours for nothing..."

Interviewer: "What were you hoping to get?"

Participant: "Answers! How do you file? Where do you file? What can you expect to get? You know, what are we eligible for?"

Issues with information and communication with goverment agencies belied a larger issue of trust in the people and agencies directly responsible for administering the buyout. When asked whether or to what degree they trusted the agencies involved in the buyout, responses were mixed. Some participants were unequivocal in their belief that the participating agencies would ensure that the program moved forward as planned, and that they were acting in the best interests of the residents:

"The governor's people have made it clear. They're moving forward with everyone who wants to move forward. Who agrees to that buyout. They will be taken care of swiftly, quickly, and done so we can move on with our lives.

God gave us this. God gave this to us. The governor brought this to us. God is watching over us...now as it stands? You're getting 15\%, you're getting bought out, you're getting fair market value."

For others, experiences with buyout administrators and other officials caused them to question whether there was a sound plan in place for the implementation of the program and, more to the point, whether the government had the residents' best interests in mind.

"It's federal, I guess, so, I mean, you should trust the government. But, you know, then again, I just, I don't know what they're planning to do. Is there any actual plan?

I went down there, [the Department of Buildings] had slapped green sticker on my house that they had came to my house, on a Sunday, at 3 o'clock in the afternoon, and did a thorough interior and exterior examination of my house, and my house was perfectly sound. I'm like, really!...I said how did you relock my deadbolts on my doors when you got out of my house, 'cause there was nobody there for you to let you in. They never explained that to me. So, we knew at that point, that they were just slappin' stickers on houses for the sake of slappin' the stickers on houses. So, right there, we're all, the whole neighborhood is like, this is ridiculous, because we can't trust the people that are supposed to be helping us."

These issues were further compounded by competing goals at the city and state levels. While the State of New
York was pushing for buyouts, New York City developed a recovery plan that prioritized the redevelopment of Sandy-damaged properties. As one official stated, the City was "hoping that people will buy several of these small lots, and then build a bigger house on them." For residents making major decisions about housing, this added yet another layer of confusion. One participant, in expressing her exasperation about the process, stated "[Mayor] Bloomberg is pushing people to rebuild, at the same time [Governor] Cuomo is pushing the buyout."

It is worth noting that participants' expectations for government agencies during and after the buyout were shaped by a history of perceived failures by multiple levels of government. Oakwood Beach was established as a summer beach community, and over time the beach homes were converted into year-round residences. There was a wave of new development beginning in the 1990s that, as reported by participants, ignored a series of mitigation recommendations proposed by the Army Corps of Engineers. Long-term residents attributed increases in local flooding events, including a significant flood in 1992, to these changes. Sandy amplified these concerns and raised questions about why the local government, given their knowledge that the land was vulnerable, had ever allowed it to be developed as permanent housing:

"Certain areas that, 50, 60, 80 it might be, years ago, never should have been allowed to be year-round. Or made year-round. Never should have even been allowed to be a bungalow area. Never mind homes. Jumping forward into the 80 s and 90 s, homes like my own included! Shouldn't a been allowed to be built three stories, shouldn't a been allowed to be where they were, so close. I mean, Oakwood Beach, the ocean's up here. And, the street and the homes are down below. You got a sewage plant a half a block away, that did release."

\subsection{The Waiting Is the Worst Part}

Compared to previous buyout efforts (c.f. buyouts associated with Hurricane Katrina), the Oakwood Beach Buyout launched without delay and did not overstay its welcome. Throughout the process, residents were told that the buyout was moving faster than any buyout had before, and the goal set by community leaders to have the first buyout home purchased within a year of the storm was realized (Sedon, 2013). In retrospect, participants' generally agreed that the buyout program moved relatively quickly. Participants stated that "the New York state buyout was clear-cut and expeditious" and that "it went completely smooth. I think it went fast."

The speed at which the program began and ended, however, was not the only factor that shaped how participants understood and experienced their progression through the buyout program. In the interim between the announcement of the buyout and the actual sale of properties, participants conveyed the stress and difficulty as- 
sociated with not knowing when, or even if, their homes would be purchased, a set of experiences that link back to our previous discussion about trust:

"They don't understand the anxiety-we've lost all our stuff, we're trying to fix our homes, but we're not getting any information. They want us to live a normal life. How do you live a normal life?"

Homeowners described the year between Sandy and the first home purchase as a constant state of waiting: waiting to learn what the state's offer on their house would be, waiting for the results of inspections, waiting for help from FEMA and insurance companies, waiting to see how high the new flood insurance rates would be, and waiting to see whether the sale of their homes would actually go through. Each step in this process was uncharted territory. As one participant stated, "The waiting is the worst part of the buyout."

Participant 1: "Well I am a little stressed out."

Participant 2: "Yeah, she's washed up."

Participant 1: "You know what it is, too, you're up in the air. You don't know what you're gonna do."

"It could have been faster. Also people were taking advantage of some of it, too. They had no insurance, they got paid right away. Us, we've been waiting and waiting and waiting. It doesn't seem fair. People who had no insurance got paid right away, people who had insurance had to wait and fight."

Housing issues topped many participants' list of challenges during this ambiguous period. Residents left with uninhabitable homes after Sandy struggled to find interim housing. Neither the city nor the state provided emergency housing, ${ }^{2}$ leaving affected residents living in a rented apartment, living with family or friends, or repairing and moving back into their damaged homes:

"Okay, in the interim we were staying, um, first we were stayin' at my mother's, then my sister's, then my brother had us stay in his apartment, and he had to move out. So we had to pay him rent.

Nobody's [living in the neighborhood] for 6 months. We don't know what's going on. I gotta tell the truth. They just came back. That-nothings moving that quickly, 'cause they're telling you they're gonna buy you out, and, look at all the work we did [repairing our house]. You know? We tried. But if they can't fix the beach up, you gotta get outta here.

We got our life back in order. Uh, we, as you can see we fixed up our house. Probably, if not equal to, a little bit better than what we had."

Each of these temporary living arrangements came with its own set of challenges, and it was not unusual for participants to have done all three. Residents who rented apartments faced the financial burden of paying rent in addition to the mortgage on their damaged home. Residents who stayed with family and friends described the social stressors associated with that choice, especially as these arrangements became longer-term. For some residents, repairing their homes became the best option, even believing that a buyout was imminent.

\subsection{They Have No Options}

One of the fundamental requirements of home buyout programs in the U.S. is that they must be voluntary, meaning that homeowners cannot be forced to participate. While policy safeguards are in place to protect residents from forced participation, the distinction between voluntary and involuntary is less straightforward than it may appear. Implementing agencies may attempt to influence participants' decisions using policy tools such as moratoria on construction, the condemnation of homes deemed abandoned, or the use of the substantially damaged declaration, where the cost of repairing a home is determined to exceed $50 \%$ of the home's predisaster value. In cases where the substantially damaged declaration is invoked, homeowners may be required to implement costly mitigation measures, such as raising the home above the base flood elevation if they wish to rebuild. For homeowners with limited financial means, the implications of this policy are not dissimilar to that of forced relocation. More subtle approaches may have a similar effect, ranging from threats to reduce services or not rebuild critical infrastructure to emphasizing the threat of future hazards or the potential social and economic impacts of rejecting a buyout when most of one's neighbors relocate (de Vries \& Fraser, 2012). There are a number of circumstances, then, under which buyout programs that are technically voluntary may not be perceived as such by residents.

In New York's buyout, the experiences and perceptions of participants raised questions as to whether, or to what degree, the program could truly be considered voluntary. One participant stated clearly "People are being forced into leaving. They have no options." While language this direct was unusual, participants described several more nuanced ways in which fears and consequences (real and threatened) made the buyout feel like less of a choice and more like their only real option.

Prior to Hurricane Sandy, residents of Oakwood Beach valued the sense of safety their neighborhood provided. The damage and destruction caused by Sandy, however, violated this sense of safety. The structural mit-

\footnotetext{
${ }^{2}$ Some participants did receive rental assistance from FEMA, though this process was described as difficult and stressful to the point that several participants simply gave up trying to access it.
} 
igation measures that had been in place failed, including a berm that separated the community from the ocean. This led many residents to believe that nothing could make the community safe from future hazards. This perception was anchored by previous disaster experience and perpetuated by buyout organizers and officials:

"So knowing that it was already compromised, one of the biggest decisions to me was they'll never get that area back. Everything was totally destroyed, the flood gate, the sea gate, the beach area, everything. It's basically a flat area, so that was one of the biggest decisions for us, that it would never, ever. Even a simple storm at this point is a threat to that area.

Some I'm sure are not back yet in their homes, but it doesn't stop the fact that this will happen again and some of us may not be that lucky again...please don't leave us here in danger there are children, handicap, elders, just simple working people trying to be in a safe place. Now even just a heavy rainfall can make me very scared and my neighbors feel the same way. Our lives have changed tremendously."

In addition to fears about safety, participants described a suite of potential consequences, including loss of choice, for residents who rejected the buyout. While the use of eminent domain is technically prohibited in buyouts, residents still feared that it would be used to forcibly relocate remaining households after the buyout, and that the purchase price of the properties would be lower. For others, the primary concern was that the housing market in Oakwood Beach would never recover after Sandy:

"Yeah, so when it goes into effect, and, you know, $80 \%$ of the houses are gone, or something like that, there's nothing to stop the state from invoking, um, eminent domain....So I think that's the fear, or that's the risk. If everyone else takes it, and you don't take it, you know. That, you may be forced into a different sort of arrangement. I have no idea if that would happen, I have no idea if there's a plan for that. But I think that's one of the dangers.

I do know a few of 'em don't wanna leave....But they're not thinking straight. Because if and when they ever go to sell their house, because of the other houses are gonna be knocked down and it's all gonna be brought back to nature, everybody's gonna remember exactly what happened. So you are never going to get the money you could've gotten through this buyout. Because they're giving us before flood prices. So even if you fix your house up perfectly now, it's not worth what it was October 28. Just because of what happened on October 29."

Participants were also concerned that potential increases in their flood insurance premiums would make staying in their homes a financial impossibility. Fueled by a national debate on the viability of the National Flood Insurance Program and the passing of the controversial Biggert-Waters Flood Insurance Reform Act in 2012, rumors spread of insurance rate hikes in excess of $\$ 20,000$ per year, an untenable amount for Oakwood Beach's working class households:

"I mean in all honesty, I would live in the house on stilts if it was on the water. I love the water, but the reality is, um, what kills us, is the flood insurance. You know, because of course the bank's not going to give you more because you don't have flood insurance, and to get flood insurance, it's just crazy what they want to charge you for flood insurance because no one wants to insure you. So that's the dilemma and the kind of stress that you deal with when you want to live in a particular neighborhood or a beachfront property. It creates a lot of stress in terms of the banks and insurance companies and all that kind of stuff."

While buyouts are voluntary by nature, then, our data indicate that this, too, is an area of potential variation across programs. The degree to which New York's program was truly voluntary was influenced not just by the technical design of the program, but also the way in which the buyout option was presented relative to other options and by the broader recovery context.

\section{Conclusions}

In this paper we have explored how key design components of home buyout programs impact household experiences and outcomes. In our case study of Oakwood Beach, New York, we found that decisions about program inclusion were originally based on familiar metrics, but were ultimately limiting and perceived as arbitrary. Financial incentives employed to encourage participation were not just high, but possibly the highest on record. At the same time, while they did appear to encourage participation, these incentives did not necessarily relieve the financial burden for buyout participants, whose primary concern was their ability to secure appropriate, desirable, and equivalent new housing. The relatively low level of government involvement was not necessarily a distinguishing feature, though the program was shaped by a history of mistrust of the government and complicated by competing goals at the city and state levels. While the buyout progressed relatively quickly, the salient issue from the participants' perspective was not the pace of program implementation, but rather their own progression through the buyout process and their ability (or inability) to access coherent, accurate, and timely information needed to make important decisions. Lastly, a theme emerged related to the voluntary nature of buyouts, an issue that has been previously raised in the literature (de Vries \& Fraser, 2012; Fraser, Elmore, Godschalk, \& Rohe, 2003). In keeping with findings from 
these studies, the buyout in New York was technically voluntary, though there were gray areas in terms of how this was perceived and experienced by participants. In the New York buyout, then, individual program components were tied to experiences and outcomes. This has implications for practice, as it suggests that even seemingly minor differences in program design may have significant impacts on affected households and communities.

While we maintain that the extant literature on home buyout programs is too sparse to draw conclusions about their viability or desirability as a disaster recovery tool, our findings offer some suggestions as to how the experience of buyouts may be improved in cases where they are implemented, or more speficially, how the experience of New York's buyout might have been improved for affected residents. We have previously drawn attention to the need for greater transparency at the implementing agency level (Greer \& Binder, 2016). In this case, greater transparency may have reduced confusion and frustration around the issues of program inclusion and eligibilty for incentives, assuaged fears regarding future uses for acquired properties, and enabled residents to make more informed decisions throughout the process. A clear, consistent, and accurate description of steps involved in the buyout process, perhaps in the form of an annotated timeline, would have allowed participants to more accurately track their progress, understand the process, and consider any avilable alternatives. In terms of the lived experiences of affected residents, the inability of the city and state to cooperate in developing and presenting recovery program options is inexcusable, and served to add confusion to an already difficult process. Given that the financial incentives provided, while substantial when compared to previous programs, were not adequate to meet participant needs, their effectiveness could have been increased through supports that assisted participants in locating appropriate, affordable homes in their desired areas. Taken together these changes, while simple, may have ameliorated a host of participant concerns.

We must consider these findings in light of the fact that, while New York's buyout program reflected some characteristics of previous programs, on the whole this was a unique program in a long line of unique programs (Greer \& Binder, 2016). By comparison, Louisiana designed a complicated buyout program after Hurricanes Katrina and Rita that was characterized by a novel, though arguably problemmatic, combination of financial disincentives and restrictions (Green \& Olshansky, 2012). Studies suggest that this program, in addition to being difficult for participants to understand and navigate, hindered recovery and reinforced pre-existing economic and social inequalities, especially in New Orleans (Gotham, 2014; Green, Bates, \& Smyth, 2007; Green \& OIshansky, 2012). In buyout programs, then, the devil may be in the details. This signals a need to increase our understanding of the relationship between policy, design, experience, and outcomes across a range of buyout pro- grams, each of which are characterized by a range of program components. This is an important step toward developing a more comprehensive theory of postdisaster relocation, and in establishing an empirical foundation for minimizing risk to buyout participants and informing best practices in all phases of the buyout process.

We offer two specific recommendations for improving buyout policy and practice. First, given the broad range of buyout programs, the variety of contexts in which they are considered and implemented, and the recent climate-induced relocations in the U.S. (Davenport \& Robertson, 2016; Kennedy, 2016), there is a clear need for an expanded research agenda in this area. Here, we highlight two specific areas that warrant greater attention. To expand our understanding of how program design relates to experiences and outcomes, we recommend that future studies examine the role of implementing agencies. These agencies have received little attention in the literature (Kick, Fraser, Fulkerson, McKinney, \& de Vries, 2011), though they could contribute significantly to our understanding of how programs are conceived, designed, and supported. More generally, the literature is silent on a primary, overarching question: are people better off for having participated in home buyout programs? Previous studies suggest that buyout participants may be subjected to a variety of risks, and without empirical studies to document the potential benefits of buyouts to the households that participate we cannot, either at a policy or household level, give an informed response to this question.

Second, in cases where buyouts are considered a viable option, we cannot overstate the importance of including local communities in the process. The true test of home buyout programs is arguably their impact on affected households and communities. Whether they are considered successful or unsuccessful in any given context, they are enormously disruptive. As such, we recommend that, at the local level, buyout programs be community-led. While an exploration of the process of community inclusion in buyouts is beyond the scope of this paper, the limited literature on buyouts suggests that community engagement in the buyout process improves outcomes (Fraser, Doyle, \& Young, 2006; Knobloch, 2005), and participation in the planning process is a consistent push of the larger recovery research community (Berke \& Campanella, 2006; Oliver-Smith, 1991; Smith, 2011). We recommend that implementing agencies prioritize the inclusion of community perspectives at all stages of the buyout process, including determining where buyouts are (and are not) implemented and developing viable alternatives with communities and households that reject buyouts. Relatedly, involving the community in planning for recovery prior to a disaster event may prevent post-disaster rebuilding that undermines the efficacy of hazard mitigation projects, including relocations (FEMA, 2009). While examples of success on this front are limited, previous studies have noted the benefit of planning for post-disaster recovery and push 
all levels of government to spend the time to create these plans (Berke, Kartez, \& Wenger, 1993; Mileti \& Passerini, 1996; Paul, Che, Stimers, \& Dutt, 2007; Rubin, Saperstein, \& Barbee, 1985). In the case of buyouts, recovery planning presents an opportunity to identify high-risk areas, begin a conversation with the community about buyouts as a possible mitigation measure, and evaluate the potential social, economic, and environmental impacts of a buyout program, before a crisis occurs.

\section{Acknowledgements}

This work was supported by the Natural Hazards Center Quick Response Grant Program (funded by National Science Foundation) [grant number CMMI1030670] and the Center for Advanced Infrastructure and Transportation (CAIT) at Rutgers University through the University Transportation Center Program (funded by the U.S. Department of Transportation) [grant number DTRT12-GUTC16].

\section{Conflict of Interests}

The authors declare no conflict of interests.

\section{References}

Badri, S. A., Asgary, A., Eftekhari, A. R., \& Levy, J. (2006). Post-disaster resettlement, development and change: A case study of the 1990 Manjil earthquake in Iran. Disasters, 30(4), 451-468.

Berg, B. L., \& Lune, H. (2012). Qualitative research methods for the social sciences. NJ: Pearson Education.

Berke, P., \& Campanella, T. (2006). Planning for postdisaster resiliency. Annals of the American Academy of Political and Social Science, 604, 192-207.

Berke, P., Kartez, J., \& Wenger, D. (1993). Recovery after disaster: Achieving sustainable development, mitigation and equity. Disasters, 17(2), 93-109. doi: 10.1111/j.1467-7717.1993.tb01137.x

Blaze, J. T., \& Shwalb, D. W. (2009). Resource loss and relocation: A follow-up study of adolescents two years after Hurricane Katrina. Psychological Trauma: Theory, Research, Practice, and Policy, 1(4), 312-322. doi:10.1037/a0017834

Davenport, C., \& Robertson, C. (2016, May 2). Resettling the first American "Climate Refugees". The New York Times. Retrieved from http://www.nytimes.com/ 2016/05/03/us/resettling-the-first-american-climate -refugees.html?_r=0

David, E., \& Mayer, J. (1984). Comparing costs of alternative flood hazard mitigation plans: The case of Soldiers Grove, Wisconsin. Journal of the American Planning Association, 50(1), 22-35.

de Vries, D. H., \& Fraser, J. C. (2012). Citizenship rights and voluntary decision making in post-disaster U.S. floodplain buyout mitigation programs. International Journal of Mass Emergencies and Disasters, 30(1), 1-33.
Dillman, D. A. (1978). Mail and telephone surveys: The total design method. New York, NY: Wiley.

Federal Emergency Management Agency. (2009). National disaster housing strategy. Retrieved from https://www.fema.gov/media-library-data/2013072 6-1747-25045-0314/the_national_disaster_housing strategy.pdf

Fox Beach 165. (2013). About us. Retrieved from http://foxbeach165.com/about-us

Fraser, J. C., Doyle, M. W., \& Young, H. (2006). Creating effective flood mitigation policies. Eos, Transactions American Geophysical Union, 87(27), 265-270.

Fraser, J. C., Elmore, R., Godschalk, D., \& Rohe, W. (2003). Implementing floodplain land acquisition programs in urban localities. NC: Chapel Hill Press.

Gotham, K. F. (2014). Racialization and rescaling: PostKatrina rebuilding and the Louisiana Road Home Program. International Journal of Urban and Regional Research, 38(3), 773-790. doi:10.1111/14682427.12141

Governor's Office of Storm Recovery. (2014). NY Rising buyout and acquisition policy manual. Retrieved from https://stormrecovery.ny.gov/sites/default/files/uplo ads/nys_buyouts_policy_manual_20140407.pdf

Green, R., Bates, L., \& Smyth, A. (2007). Impediments to recovery in New Orleans' Upper and Lower Ninth Ward one year after Hurricane Katrina. Disasters, 31(4), 311-335.

Green, T. F., \& Olshansky, R. B. (2012). Rebuilding housing in New Orleans: The Road Home Program after the Hurricane Katrina disaster. Housing Policy Debate, 22(1), 75-99.

Greer, A., \& Binder, S. B. (2016). A historical assessment of home buyout policy: Are we learning or just failing? Housing Policy Debate. doi:10.1080/10511482. 2016.1245209

Hori, M., \& Schafer, M. J. (2009). Social costs of displacement in Louisiana after Hurricanes Katrina and Rita. Population and Environment, 31(1/3), 64-86. doi:10.1007/s11111-009-0094-0

Hurricane Sandy Rebuilding Task Force. (2013). Hurricane Sandy rebuilding strategy. Retrieved from http:// portal.hud.gov/hudportal/documents/huddoc?id=H SRebuildingStrategy.pdf

Kaplan, T. (2013, February 3). Cuomo seeking home buyouts in flood zones. New York Times. Retrieved from http://www.nytimes.com/2013/02/04/nyregion/cuo mo-seeking-home-buyouts-in-flood-zones.html

Kennedy, M. (2016, August 18). Threatened by rising seas, Alaska village decides to relocate. National Public Radio. Retrieved from http://www.npr.org/sectio ns/thetwo-way/2016/08/18/490519540/threatened -by-rising-seas-an-alaskan-village-decides-to-relocate

Kessler, R. C., Galea, S., Gruber, M. J., Sampson, N. a, Ursano, R. J., \& Wessely, S. (2008). Trends in mental illness and suicidality after Hurricane Katrina. Molecular Psychiatry, 13(4), 374-384. doi:10.1038/sj.mp. 4002119 
Kick, E. L., Fraser, J. C., Fulkerson, G. M., McKinney, L. a, \& de Vries, D. H. (2011). Repetitive flood victims and acceptance of FEMA mitigation offers: An analysis with community-system policy implications. Disasters, 35(3), 510-539. doi:10.1111/j.1467-7717.2011.0122226.x

Knobloch, D. M. (2005). Moving a community in the aftermath of the Great 1993 Midwest Flood. Journal of Contemporary Water Research \& Education, 130(1), 41-45. doi:10.1111/j.1936-704X.2005.mp13 0001008.x

Mileti, D., \& Passerini, E. (1996). A social explanation of urban relocation after earthquakes. International Journal of Mass Emergencies and Disasters, 14(1), 97-110.

Milne, G. (1977). Cyclone Tracy: I Some consequences of the evacuation for adult victims. Australian Psychologist, 12(1), 39-54.

Mortensen, K., Wilson, R. K., \& Ho, V. (2009). Physical and mental health status of Hurricane Katrina evacuees in Houston in 2005 and 2006. Journal of Health Care for the Poor and Underserved, 20(2), 524-538. doi:10.1353/hpu.0.0130

New York State Homes and Community Renewal. (2013). State of New York action plan for Community Development Block Grant program disaster recovery. Retrieved from http://www.nyshcr.org/Publica tions/CDBGActionPlan.pdf

NY Rising. (2014). State announces expanded enhanced buyout area to include the Graham Beach area. Retrieved from http://stormrecovery.ny.gov/sit es/default/files/uploads/graham_beach_release.pdf

Office of Community Renewal. (2013). State of New York action plan for Community Development Block Grant program disaster recovery. Retrieved from www.nyshcr.org/Publications/CDBGActionPlan.pdf

Oliver-Smith, A. (1991). Successes and failures in postdisaster resettlement. Disasters, 15(1), 12-23. doi: 10.1111/j.1467-7717.1991.tb00423.x

Paul, B. K., Che, D., Stimers, M., \& Dutt, S. (2007). "Disaster in Kansas": The tornado in Greensburg. Retrieved from https://hazards.colorado.edu/uploads/ quick_report/paul_2007.pdf
Riad, J. K., \& Norris, F. H. (1996). The influence of relocation on the environmental, social, and psychological stress experienced by disaster victims. Environment and Behavior, 28(2), 163-182.

Rizzi, N. (2014, April 11). State won't add any more neighborhoods to Sandy buyout program. DNAinfo. Retrieved from http://www.dnainfo.com/new-york/ 20140411/new-dorp-beach/state-will-add-no-moreneighborhoods-sandy-buyout-program

Rubin, C., Saperstein, M., \& Barbee, D. (1985). Community recovery from a major natural disaster. CO: Institute of Behavioral Science-University of Colorado Boulder.

Saldaña, J. (2012). The coding manual for qualitative researchers (2nd ed.). CA: SAGE Publications.

Sanders, S., Bowie, S. L., \& Bowie, Y. D. (2003). Chapter 2 lessons learned on forced relocation of older adults. Journal of Gerontological Social Work, 40(4), 23-35.

Sedon, M. (2013). First Staten Island home bought out by state after Hurricane Sandy is demolished. Staten Island Live. Retrieved from http://www.silive.com/ news/index.ssf/2013/10/first_oakwood_beach_hom e_bough.html

Smith, B. G. (2011). Planning for post-disaster recovery: A review of the United States disaster assistance framework. Washington D.C.: Island Press.

Tobin, G. A., \& Peacock, T. (1982). Problems and issues in comprehensive planning for a small community: The case of Soldiers Grove, Wisconsin. The Environmental Professional, 4(1), 43-50.

Weber, L., \& Peek, L. (2012). Displaced: Life in the Katrina diaspora. Austin, TX: University of Texas Press.

Yin, R. K. (2013). Case study research: Design and methods. CA: SAGE Publications.

Yzermans, C. J., Donker, G. a, Kerssens, J. J., Dirkzwager, A. J. E., Soeteman, R. J. H., \& ten Veen, P. M. H. (2005). Health problems of victims before and after disaster: A longitudinal study in general practice. International Journal of Epidemiology, 34(4), 820-826. doi:10.1093/ije/dyi096

\section{About the Authors}

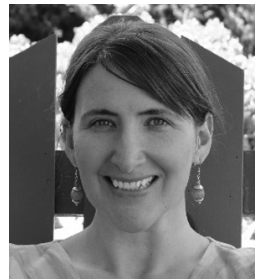

Sherri Brokopp Binder, PhD, is President of BrokoppBinder Research \& Consulting, a research and evaluation firm based in Allentown, PA. Her research is focused on household decision-making and recovery after natural disasters, with an emphasis on postdisaster relocation. Her recent work includes qualitative and mixed-methods studies on the 2009 South Pacific tsunami in American Sāmoa, Hurricane Sandy, and the Moore, OK tornadoes. Sherri is also the director of a non-profit organization that addresses issues related housing and social integration in urban community contexts.

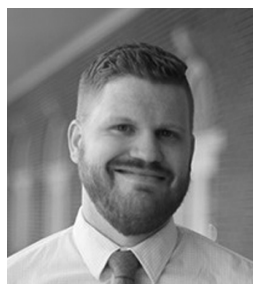

Alex Greer, PhD, is an Assistant Professor in the Political Science Department at Oklahoma State University where he teaches graduate courses in the Fire and Emergency Management Program. He conducts interdisciplinary, mixed methods research on a number of elements of disaster science. Recent projects focused on: risk perception and hazard adjustment related to earthquakes in Oklahoma, household residential decision-making in disaster recovery and the role infrastructure plays in this process, archival disaster research on mental health response, and the relationship between issue framing and oil spill policy. 